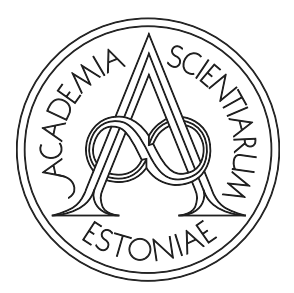

Proceedings of the Estonian Academy of Sciences, $2021,70,4 S, 347-353$

https://doi.org/10.3176/proc.2021.4S.06

Available online at www.eap.ee/proceedings

COGNITIVE PSYCHOLOGY

\title{
The relationship between visual perception and word meaning structure: an explorative study
}

\author{
Valeri Murnikov
}

The Centre of Excellence in Behavioural and Neural Sciences, School of Natural Sciences and Health, Tallinn University, Narva mnt 25 , 10120 Tallinn, Estonia; valeri.murnikov@tlu.ee

Received 1 November 2020, accepted 9 June 2021, available online 10 October 2021

(C) 2021 Author. This is an Open Access article distributed under the terms and conditions of the Creative Commons AttributionNonCommercial 4.0 International License (http://creativecommons.org/licenses/by-nc/4.0/).

\begin{abstract}
Visuospatial ability is often considered a distinct nonverbal cognitive function. However, previous studies have suggested that visuospatial abilities are semiotically mediated, and therefore, they cannot be considered completely nonverbal. These studies have shown empirically and theoretically that, for example, higher visuospatial abilities such as visual discrimination and mental rotation are semiotically mediated. In this explorative study, we examined the relationship between word meaning structure and visual perception. This study relies on the results of two tasks obtained from a larger test battery measuring different aspects of speech and cognition. The first task measured visual perception and the ability to inhibit the distracting stimuli; in the second task, we measured the individuals' dominant conceptual thought. The sample consisted of 58 native Estonian speakers. The results indicated three different behavioural patterns while solving visual-perceptual tasks. Two of the behavioural patterns relied on verbalization during the process of task solving. The participants who used verbalization had less dominant logical conceptual thought. Theoretically, verbalization suggests that participants find a given task cognitively demanding. The fact that the majority of the participants verbalized the process in connection with word meaning structure supports the idea that visuospatial abilities are not totally nonverbal, but rather semiotically mediated.
\end{abstract}

Key words: visuospatial abilities, perception, word meaning structure, explorative study.

\section{INTRODUCTION}

Visuospatial abilities are often seen as a distinct system of cognitive processes. According to Linn and Petersen (1985), visuospatial abilities refer to skills in representing, transforming, generating, and recalling symbolic nonlinguistic information. These abilities could be divided into three categories (Linn and Petersen 1985): spatial perception is an ability to understand spatial relationships with respect to the orientation of one's own body; mental rotation is an ability to mentally rotate two- or threedimensional perceived objects; and spatial visualization is an ability to perform more complex tasks involving multiple operations with perceived information (i.e., similar to mental rotation). Visuospatial abilities are typically categorized as nonverbal or independent from verbal abilities. For example, Baddeley's model (1992) of working memory distinguishes verbal (i.e., phonological loop) and visual (i.e., visuospatial sketchpad) working memory as separate processes. Paivio's dual-coding theory (1990; Clark and Paivio 1991) similarly distinguishes distinct cognitive systems for processing nonverbal (imaginary) and verbal information. From a methodological point of view, visuospatial abilities are commonly studied based on psychometric models (e.g., Johnson and Bouchard Jr. 2005).

Toomela et al. (2019) explained that categorizing visuospatial abilities separately from verbal abilities is contrary to the concept of higher psychical function (a concept originally suggested by Vygotsky; for discussion, see Luria 1969; 1979; Toomela 2016a; 2016b; Toomela et al. 2019). The concept of higher psychical 
functions relies on the assumption that all psychical functions are semiotically mediated. It has been shown that word meaning structure is associated with visuospatial abilities. Recent studies have indicated that there is a relationship between dominant logical thought and visuospatial abilities (Tammik and Toomela 2013; Toomela et al. 2019). These findings suggest that analysis of visuospatial sensory information is semiotically mediated. Moreover, the development of word meaning structure underlies qualitative changes in the ability to analyse sensory information (Toomela et al. 2019).

Word meaning structure refers to how words relate to thought (Vygotsky 1934; Luria 1979). The relationship between words and thought is indirect and depends on the meaning of the word according to the individual. Word meaning is a form of generalization (i.e., concept formation) and is part of the thought process. Word meaning structure develops starting from syncretic concepts in which a word is tied to a concrete situation, resulting in variable meaning depending on the situation. When word meaning structure reaches the stage of everyday concepts, this means that the meaning of the word is tied to sensory attributions of objects and actions observed in everyday situations. Logical concept words are more abstract, organized both hierarchically and logically. The development of word meaning structure underlies qualitative changes in cognitive processes. The development of logical concepts allows an individual to mentally analyse sensory information in a more abstract way (Toomela et al. 2019). Prior studies have examined the relationship between dominant logical word meaning structure, discrimination, and mental rotation (Tammik and Toomela 2013; Toomela et al. 2019). The findings indicate that better performance in visuospatial tasks is related to more dominant logical thought. Individuals for whom only everyday concepts are available show difficulties in finding abstract contours and solving mental rotation tasks. This suggests that the development of word meaning structure is related to qualitative changes in visuospatial abilities.

Similarly to Linn and Petersen's (1985) description of visuospatial abilities, Luria (1969) distinguishes three categories in the study of visuospatial abilities: visual perception of objects and representations, spatial orientation, and spatial intellectual operations. The latter two processes have been examined in relation to the development of word meaning structure (Tammik and Toomela 2013; Toomela et al. 2019), but the first process has not.

Although the visual perception of objects and representations is more primitive than spatial orientation and spatial intellectual operations, it is also a more complex process. According to Luria's (1969) description, the perception of objects or representations relies on complex optical stimuli, and accurate visual perception is built on several assumptions: appropriate examination of the object, distinguishing its essential features, establishing their relationship, and integrating essential features into common patterns that determine the final perception of the object. This process requires inhibition of unnecessary stimuli and correction of perceptual errors resulting from premature evaluation. Luria (1969) noted that participants who found visuospatial tasks cognitively demanding started verbalizing or using fingers to help solve the tasks. Luria (1969) proposed that verbalization and gesticulation could theoretically be additional tools for mediating sensory information as this type of behaviour has been shown in people with brain injuries. Thus theoretically, healthy individuals who verbalize distracting stimuli, may struggle with cognitive inhibition and the ability to filter out irrelevant information. This behaviour could refer to an inability to mentally separate and analyse sensory information in an abstract form - an ability that is a qualitative feature of thought on the logical concept stage (Toomela et al. 2019).

There are numerous ways to solve visuospatial tasks, thus it is difficult to analyse responses without acknowledging concrete behaviour (for discussion, see Toomela 2008; 2009). Solving visual-perceptual tasks may rely on different behaviours, and by assessing the behaviour, researchers may better understand when and for whom the tasks are cognitively more demanding.

\section{THE PRESENT STUDY}

The concept of higher psychical functions assumes a hierarchical relationship between cognitive processes. Hierarchically, visual perception of objects is a prerequisite for higher visual processes such as visual discrimination and/or mental rotation. Prior research has studied the relationship between visual perception and word meaning structure not directly, but as part of hierarchically higher visuospatial abilities (Tammik and Toomela 2013; Toomela et al. 2019).

The main aim of this explorative study was to investigate the relationship between visual perception and word meaning structure. First, we examined behavioural differences when solving visuospatial tasks. We were interested in understanding which behaviours occur when solving an object-naming task and if any patterns emerge. Next, we investigated the association between different behaviours and word meaning structure.

\section{METHOD}

\subsection{Participants}

The sample was comprised of 58 native Estonian speakers (33 males, 25 females; mean age $=70.71 ; S D=9.84$ ). 
Nine participants had finished primary school, 29 had finished secondary school, 6 had bachelor's degrees, 12 had master's degrees, and 2 doctoral degrees.

\subsection{Materials and methods}

This study relied on the results from a larger test battery created by Aaro Toomela which measured different aspects of speech and cognition. The study was approved by the Research Ethics Committee of the University of Tartu (275/M-27). All participants were tested individually. The testing process was audio recorded and later transcribed. The participants were told about the aims of the study and informed that all data would be analysed anonymously, that participation was voluntary, and that their participation could be stopped at any time.

\subsubsection{Visual perception}

Visual perception was assessed via a task created by Luria (1969, page 304), which is an easier version of Poppelreuter's Task (1917). Nine cards were presented separately, each with one of three different objects (bottle, clothespin, or pacifier) and one of three distracting contour variations overlapping the objects (spiral, zigzag, or no distracting contour) (Fig. 1). These particular objects were chosen to present common objects with concrete contours seen in everyday life and less common objects with more ambiguous contours. Each card was presented separately. First, the participants were asked to name only the object on the card. When the first card with distracting contour was presented, the researcher gave the following instructions, "Here is an object with a zigzag drawn on it.
Please name the object that is under the drawing." Despite the contour variation, verbal instructions given by the researcher never changed: the participants were asked to name only the object on the card. Theoretically, if there is a difference between the two conditions (i.e., with and without contour), then that difference refers to the process of perception that is not externally related to the condition. The answers were coded as correct (1) or incorrect (2). Based on the audio transcriptions, the researcher divided the answers into categories (discussed further in the results section). To ensure coding reliability, a research assistant re-coded all of the data. Inter-rater coding was measured using Cohen's kappa $(\kappa=0.707)$.

\subsubsection{Word meaning structure}

The word meaning task consisted of two parts. In the first part, the participants were instructed to define three words which varied from concrete (e.g., hospital) to abstract (e.g., revolution). In the second part, the participants were asked to describe how various word pairs were similar. The word pairs included either words in the same category (e.g., cat-dog) or words in a complementary relationship (e.g., hat-head). The answers were coded into two categories (following Toomela 2003): everyday concepts (1) and scientific concepts (2).

A definition was coded as an everyday concept if the definition was based on a description of related everyday activities (e.g., a 'hospital' is where doctors work) or the function of the object (e.g., a 'hospital' treats sick people). The word pairs were coded as everyday concepts if the description of similarity relied on sensory attributes of the objects (e.g., 'cat' and 'dog' match because both have four
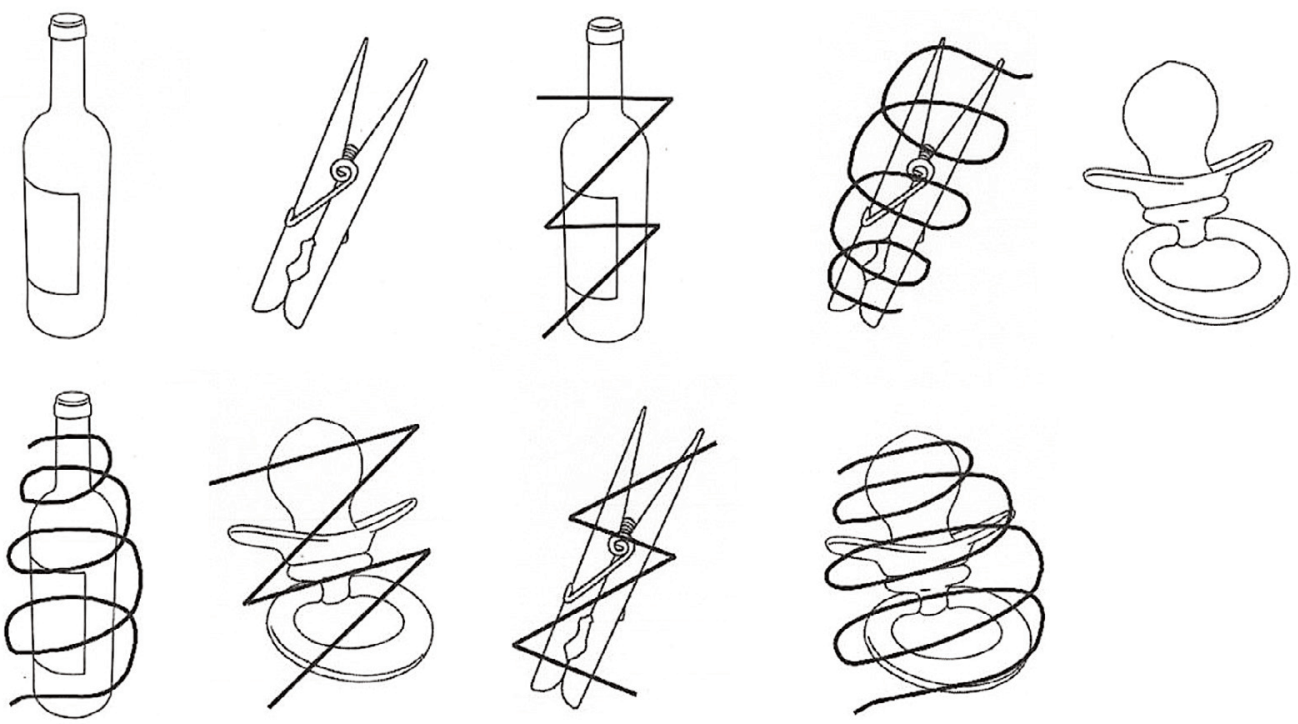

Fig. 1. Stimuli used in the visual-perception task. 
legs), similarities between objects described based on everyday situations (e.g., 'cat' and 'dog' match because they both like to be stroked), or sharing of features (e.g., 'cat' and 'dog' are similar because both are hairy). The absence of an answer was also coded as an everyday concept.

A definition was coded as a scientific concept if the definition was related to a hierarchically higher-level concept (e.g., a 'hospital' is a medical institution). Word pairs were coded as scientific concepts if the relationship between words was defined hierarchically (e.g., 'cat' and 'dog' match because both are domestic animals). The maximum score was 12 . To ensure coding reliability, $20 \%$ of the data was re-coded by a research assistant. Interrater reliability between coders was acceptable (Cohen's $\kappa=0.81)$.

\section{RESULTS}

\subsection{Visual perception}

Incorrect answers were given for the card showing a bottle with zigzag contour and for all three variants of the pacifier card (see Table 1). For the card showing a bottle with zigzag contour, one participant could not provide the correct answer; for cards showing the pacifier, eight participants could not provide the correct answer for any variation of the card, and two participants could not provide the correct answer for one variation of the card (six participants said that it was a toilet seat, one thought it was a desk lamp, one reported a light bulb, one a mirror, and one could not provide an answer). For the card showing a pacifier with zigzag contour, four participants thought it was a toilet seat, one reported a light bulb, one a hat, one a mirror, and one could not provide an answer. For the card showing a pacifier with spiral contour, three participants once again said it was a toilet seat, and four could not provide an answer.
The answers given in the visual perception task were audio recorded, and transcriptions of these recordings helped further distinguish two categories: 1) concise answers were answers that only named the object presented on the card; 2) extended answers were answers where additional information was provided about the stimuli. Concise answers were given for all of the cards without distracting contour (see Table 1). For cards with distracting contour, over half of the answers were extended answers (see Table 1).

An analysis of the extended answers revealed two main answer types: 1) answers where the participant named both the object and the contour (e.g., "bottle and zigzag" or "pacifier under a spiral drawing"); and 2) answers where the participants synthesized the object and the contour. This synthesis was made in two ways: 1) participants applied additional features to the object (e.g., for the card showing a bottle with zigzag contour, "It means the bottle is broken" or "If the bottle is crossed out then it means it is probably a vodka bottle"); or 2) participants synthesized the meaning on the basis of the object and the contour (e.g., for the card showing a pacifier with zigzag contour, "The pacifier is crossed out, which means - don't give the pacifier"). Naming the object and the contour occurred more often than synthesizing (see Table 1).

\subsection{Differences between groups}

To fulfil the second aim of the research, we studied the relationship between answer types and dominant word meaning structure. First, the participants were divided into four groups depending on the type of the answers they provided: 1) participants who provided concise answers; 2) participants who named both the object and the contour; 3) participants who synthesized the object and the contour; and 4) participants who mixed all answer variations.

To ensure homogeneity of groups in terms of age, education, and gender, we conducted the following analyses. There were no statistically significant differences

Table 1. Results of the visual-perception task

\begin{tabular}{l|c|c|c|c|c}
\hline & $\begin{array}{c}\text { Correct } \\
\text { answers }\end{array}$ & $\begin{array}{c}\text { Incorrect } \\
\text { answers }\end{array}$ & $\begin{array}{c}\text { Concise } \\
\text { answers }\end{array}$ & $\begin{array}{c}\text { Object and } \\
\text { contour }\end{array}$ & $\begin{array}{c}\text { Synthesis of } \\
\text { object and contour }\end{array}$ \\
\hline Bottle & $58(100 \%)$ & - & $100 \%$ & - & - \\
Clothespin & $58(100 \%)$ & - & $100 \%$ & - & - \\
Bottle and zigzag & $57(98.3 \%)$ & $1(1.7 \%)$ & $25.9 \%$ & $39.7 \%$ & $34.5 \%$ \\
Clothespin and spiral & $58(100 \%)$ & - & $37.9 \%$ & $32.8 \%$ & $29.3 \%$ \\
Pacifier & $48(82.76 \%)$ & $10(17.24 \%)$ & $100 \%$ & - & - \\
Bottle and spiral & $58(100 \%)$ & - & $46.6 \%$ & $31.0 \%$ & $22.4 \%$ \\
Pacifier and zigzag & $51(86.21 \%)$ & $8(13.79 \%)$ & $43.1 \%$ & $36.2 \%$ & $20.7 \%$ \\
Clothespin and zigzag & $58(86.21 \%)$ & - & $50 \%$ & $36.2 \%$ & $13.8 \%$ \\
Pacifier and spiral & $51(86.21 \%)$ & $8(13.79 \%)$ & $46.4 \%$ & $33.9 \%$ & $19.6 \%$
\end{tabular}


Table 2. Results of the word meaning structure test

\begin{tabular}{lcc|c|c|c}
\hline & Mean & Median & $S D$ & Min & Max \\
\hline Group 1 $(n=12)$ & 9.92 & 10 & 1.08 & 8.00 & 11.00 \\
Group 2 $(n=11)$ & 8.91 & 9 & 1.22 & 7.00 & 11.00 \\
Group 3 $(n=18)$ & 8.44 & 8 & 1.42 & 6.00 & 11.00 \\
Group 4 $(n=17)$ & 8.76 & 9 & 1.52 & 6.00 & 11.00
\end{tabular}

across groups in terms of gender (Fisher's exact test $\left.\chi^{2}(3)=0.904, p=0.825\right)$ or education $\left(\chi^{2}(12)=8.171\right.$, $p=0.772)$. While the Kurskal-Wallis test indicated significant differences in age $(\mathrm{H}(3)=8.376, p<0.05)$, Dunn's posthoc test with Bonferroni correction for multiple tests indicated no significant differences. We also examined differences in scores of the word meaning structure task between the participants who gave correct answers and those who gave incorrect answers; according to the Mann-Whitney $U$ test, no differences were found $(\mathrm{U}=154, p=0.294)$.

Subsequently, we compared word meaning scores between the groups to better understand the differences in word meaning structure among the participants with different behaviours. A one-way ANOVA revealed a statistically significant difference between groups $(F(3,54)=2.971, p=0.040)$. Tukey's test revealed that those participants who gave concise answers had significantly higher scores compared to the participants who provided synthesized responses $(p=0.026)$ (see Table 2). There were no statistically significant differences between other groups.

While one-way ANOVA with Tukey's test helped minimize the risk of Type I errors, there was still a risk of Type II errors given the explorative nature and small sample size of this research. Therefore, we also compared the groups pairwise. According to $t$-tests, Group 1 differed from Groups 2, 3, and 4 (see Table 2) $(t(21)=2.097$, $p=0.048 ; t(28)=3.037, p=0.005 ; t(27)=2.246, p=$ 0.033 , respectively). No differences between other groups were found. Therefore, we also examined the differences in scores of the word meaning structure test between those who gave concise answers and all other groups as one group. There was a significant difference between the participants who gave concise answers $(M=9.92 ; S D=$ $1.08)$ and those who gave extended answers $(M=8.67$; $S D=1.34)(t(56)=2.854 ; p=0.006)$.

\section{DISCUSSION}

The current study sought to address the question of whether visuospatial abilities are purely nonverbal in humans.
Previously, evidence has shown that visuospatial abilities are semiotically mediated and are related to the development of word meaning structure. Prior studies have also examined the relationship between word meaning structure and visual discrimination and/or mental rotation (Tammik and Toomela 2013; Toomela et al. 2019). This study builds on prior research with the aim of examining the relationship between word meaning structure and visual perception. To achieve this, we monitored healthy adults while solving a visual-perception task.

Our analyses revealed that most healthy adults are capable of solving the task. Some participants provided incorrect answers, especially in regard to one particular object: the pacifier. The pacifier may be considered the most complex object used in this study, which may account for the incorrect responses. Many participants who did not correctly identify the pacifier thought it was a toilet seat. Despite these incorrect responses, most healthy adults in our study were still capable of performing the task and naming the correct objects. However, there were different concrete behavioural patterns used to complete the tasks.

While naming the objects, the participants exhibited behavioural patterns which fell into three categories: 1) answers which only named the object on the card; 2) answers which named both the object and the distracting contour; and 3) answers which referred to some new object or meaning by integrating the object and the contour. These findings are related to Luria's (1969) description of visual perception as a process of distinguishing essential features of perceived stimuli, establishing their relationship, and integrating them into common categories corresponding with the presented object. The participants who directly followed the task instructions coped with all stages in Luria's (1969) model correctly. Most importantly, these participants following Luria's description (1969) did not struggle with inhibition of unnecessary stimuli and were capable of mentally ignoring distracting contours. The participants in Group 2 described both the object and the contour. Therefore, according to Luria (1969), they operated with two objects, defining them into two different categories. Theoretically, despite providing the correct answers, verbalization of the 
distracting stimuli might suggest an inability to cognitively inhibit irrelevant information (Luria 1969). However, this behaviour may also be present due to problems with memorizing task instructions or matching behaviour in accordance with the instructions. The participants in Group 3 also most likely had a problem with inhibiting unnecessary information, but with one important difference: the participants in Group 3 did not integrate the target object and the distracting contour into different categories but rather integrated both into a single novel category.

As regards the behavioural patterns described above, there appears to be a difference in behavioural complexity, especially among the participants in Group 3 who generated abstract meanings by synthesizing objects into abstract concepts. For example, answers such as 'prohibition' were given for cards showing overlapping spirals. 'Prohibition' is an abstract concept that could not be perceived as an object presented on a card. This type of answer seems to be semiotically mediated into a concept - that is, a feature of logical thought. By contrast, the participants in Group 2 simply named the objects and distracting contours separately.

The participants who simply named the object on the card (Group 1) seemingly relied on simple behaviour, but such answers are actually more complex than they appear as they require inhibition of unnecessary stimuli. These participants had the highest word meaning structure test scores, suggesting more dominant logical word meaning structure. This is consistent with the concept of word meaning structure. Answers given by the participants in Group 1 refer to the ability to mentally separate and analyse abstract sensory information. This process has qualitative features of logical conceptual thought (Toomela et al. 2019). These results support the idea described by Toomela (2016a) and Toomela et al. (2019) that the emergence of logical concepts helps 1 ) to mentally distinguish perceived information; 2) to think independently about the elements of perceived information; and $3)$ to analyse abstract elements separately from the perceived meaning. The participants in Group 1 showed an ability to solve the task by mentally operating with objects and contours. Thus, less complex behaviour when solving the task (i.e., naming only the object on the card) refers to a more complex and higher stage of logical thought.

On the contrary, the participants who seemingly demonstrated the most complex behaviour when solving the task had the lowest scores in word meaning structure. The participants in Group 3 could distinguish perceived elements but were evidently unable to analyse information independently from meaning, resulting in responses that misattributed meaning to the presented contours. This behaviour also shares features of logical concept thought.
This begs the question: if all participants' behaviours share features of logical word meaning structure, then what is theoretically different about the people who achieved the highest stage of logical thought?

Thinking is heterogeneous (Toomela 2017; Vygotsky 1934), and a person's thought can operate both in everyday and logical concepts simultaneously. In this study, the participants were tested on concepts that varied from less to more abstract. Theoretically, heterogeneity of thought could explain the differences in behaviours across groups, despite features of logical concepts being evident in all groups. The group that provided concise answers that directly followed instructions had the smallest variance in word meaning structure. Therefore, it could be argued that the participants in this group had fewer heterogeneous thoughts and logical concepts prevailed. On the other hand, the group that used the most complex behaviour to complete the task had the largest variance in word meaning structure; in fact, one participant did not provide any answers in logical concepts (though we cannot infer that the participant was only thinking in everyday concepts; see Toomela 2017; Toomela et al. 2019).

Some limitations of this explorative study should be acknowledged. First, the small sample used in this study was mostly homogenous in terms of age and education. This limits the ability to generalize our findings. Second, only a small number of stimuli and questions were used to measure word meaning structure. Third, considering the methodological approach of the study, we were not able to control all possible variables which may have influenced the results. Therefore, we cannot state that there were no other reasons for the verbalization of the task performance for the individuals. This limited study cannot fully capture the relationship between visual perception and word meaning structure. However, despite these limitations, the behavioural patterns demonstrated in this study confirm previous findings regarding visuospatial abilities as higher psychical functions. Therefore, our findings are worth reexamining with a larger sample and using more diverse conditions.

\section{CONCLUSIONS}

Our results suggest that visual perception, despite being relatively simple in terms of visuospatial abilities, might be nonetheless cognitively demanding for healthy adults. The participants did not exhibit difficulties solving the task, but their behaviours suggest differences in cognitive demands. This is consistent with Luria's (1969) findings regarding people with brain injuries. These findings are also consistent with previous studies that showed how visual perception, as a visuospatial ability, is related to word meaning structure (Tammik and Toomela 2013; 
Toomela et al. 2019). Considered jointly, these findings support the view that visuospatial abilities are not completely nonverbal but rather semiotically mediated; the majority of the participants verbalized during the process of solving the visuoperceptual task, highlighting the relationship between visual perception and word meaning structure.

Our findings align with Luria's (1969) stages of visual perception, as behavioural complexity varied theoretically in accordance with features of logical concept thought. The participants with less dominant logical word meaning structure used more complex behaviours, while those with more dominant logical word meaning structure solved the task mentally, without verbalizing the process. This is consistent with the idea that development of logical concept thought allows individuals to manipulate objects psychically and in an abstracted form.

\section{ACKNOWLEDGEMENTS}

This research was funded by Tallinn University School of Natural Sciences and Health Grant TA/2619 "Study of novel aspects of the state and development of speech function (1.01.2019-31.12.2021)". The publication costs of this article were covered by the Estonian Academy of Sciences.

\section{REFERENCES}

Baddeley, A. 1992. Working memory. Science, 255, 556-559.

Clark, J. M. and Paivio, A. 1991. Dual coding theory and education. Educ. Psychol. Rev., 3(3), 149-210.

Johnson, W. and Bouchard Jr., T. J. 2005. The structure of human intelligence: It is verbal, perceptual, and image rotation (VPR), not fluid and crystallized. Intelligence, 33(4), 393-416.
Linn, M. and Petersen, A. 1985. Emergence and characterization of sex differences in spatial ability: A meta-analysis. Child Dev., 56, 1479-1498.

Luria, A. R. 1969. Higher Cortical Functions in Man and their Disturbances in Local Brain Lesions. 2nd ed. Moscow: Izdatel'stvo Moskovskogo Universiteta, Moscow (in Russian).

Luria, A. R. 1979. Language and Mind. Izdatel'stvo Moskovskogo Universiteta, Moscow (in Russian).

Paivio, A. 1990. Mental Representations: A Dual Coding Approach. Oxford University Press, New York, NY.

Poppelreuter, W. 1917. The Psychic Damage Resulting from Head Injury in the War 1914-1916. Voss, Leipzig (in German).

Tammik, V. and Toomela, A. 2013. Relationships between visual figure discrimination, verbal abilities, and gender. Perception, 42(9), 971-984.

Toomela, A. 2003. Relationships between personality structure, structure of word meaning, and cognitive ability: A study of cultural mechanisms of personality. J. Pers. Soc. Psychol., 85(4), 723-735.

Toomela, A. 2008. Variables in psychology: A critique of quantitative psychology. Integr. Psychol. Behav. Sci., 42(3), 245-265.

Toomela, A. 2009. How methodology became a toolbox and how it escapes from that box. In Dynamic Process Methodology in the Social and Developmental Sciences (Valsiner, J., Molenaar, P. C. M., Lyra, M. C. D. P. and Chaudhary, N., eds), pp. 45-66, Springer, New York, NY. https://doi.org/ 10.1007/978-0-387-95922-1 3

Toomela, A. 2016a. Culture, Speech, and My Self. Eesti Keele Sihtasutus, Tallinn.

Toomela, A. 2016b. What are higher psychological functions? Integr. Psychol. Behav. Sci., 50, 91-121.

Toomela, A. 2017. The Development of Myself: From a Human Child to a Human. Väike Vanker, Tartu (in Estonian).

Toomela, A., Filho, D. B., Bastos, A. C. S., Chaves, A. M., Ristum, M., Chaves, S. S. and Salomão, S. J. 2019. Studies in the mentality of literates: 1 . conceptual structure and aspects of visual perception. Integr. Psychol. Behav. Sci., 54, 465-493. https://doi.org/10.1007/s12124-019-09511-5

Vygotsky, L. S. 1934. Thinking and Speech. Psychological Investigations. Gosudarstvennoje Social'no-ekonomicheskoje Izdatel'stvo, Moscow (in Russian).

\section{Visuaalse taju seosed mõistelise mõtlemisega: eksploratiivne uuring}

\section{Valeri Murnikov}

Visuaal-ruumilist võimekust käsitletakse tihti kui eraldiseisvat, aga mitte verbaalset kognitiivset funktsiooni. Samas on visuaal-ruumilised protsessid semiootiliselt vahendatud, seega ei saa neid täiesti mitteverbaalseteks pidada. Eelnevates uuringutes on empiiriliselt ja teoreetiliselt näidatud kõrgemad visuaal-ruumilised protsessid selliselt, et näiteks visuaalne objektitajumine ning mentaalne roteerimine on semiootiliselt vahendatud. Viisime läbi eksploratiivse uuringu, kus uuriti seoseid mõistelise mõtlemise struktuuri ja visuaalsete tajuprotsesside vahel. Uuringus kasutasime kaht ülesannet suuremast testikomplektist, mis mõõdab erinevaid kõne- ja kognitsioonifunktsioone. Esimeses ülesandes hindasime inimese visuaalse taju ja segavate stiimulite pärssimist, teises ülesandes mõõtsime inimeste juhtivat mõistelise mõtlemise struktuuri. Valim koosnes 58 inimesest, kelle emakeel oli eesti keel. Visuaalset taju mõõtvates ülesannetes eristasid tulemused lahendustes kolm erinevat käitumismustrit. Kaks neist olid iseloomulikud, kuna sooritusi verbaliseeriti uuritavate poolt. Need, kes verbaliseerisid oma sooritust, olid vähem domineeriva loogilise mõiste mõtlemise struktuuriga. Verbaliseerimine viitab sellele, et uuritavate jaoks oli ülesanne kognitiivselt koormav. Asjaolu, et enamik uuritavatest verbaliseeris enda sooritust ja see oli seotud mõistelise mõtlemise struktuuriga, toetab ideed, et visuaal-ruumiline võimekus pole täiesti mitteverbaalne, vaid on pigem semiootiliselt vahendatud. 